\title{
STANDARD COST OF ITALIAN METRO SERVICES: THE INFLUENCE OF AUTOMATISM, WHEELS TECHNOLOGY AND CAPACITY
}

\author{
ALESSANDRO AVENALI, GIUSEPPE CATALANO, TIZIANA D'ALFONSO \& GIORGIO MATTEUCCI \\ Department of Computer, Control and Management Engineering, Sapienza Università di Roma, Italy
}

\begin{abstract}
In this paper, we measure the standard cost of light metro (LM) and heavy metro (HM) Italian services based on the cost model provided by Avenali et al., (2018). The cost model takes into account technological characteristics that may drive cost differentials, such as the degree of automatism of the rolling stock, wheels technology and hourly peak capacity. Specifically, we focus on three case studies: (i) not automatic railway steel technology with heavy capacity; (ii) not automatic railway steel technology with light capacity; (iii) automatic rubber-tyred technology with light capacity. Data have been gathered by means of questionnaires sent to companies producing $100 \%$ of train revenue kilometers (TRK) in Italy in 2012. We perform a simulation study in order to highlight the marginal impact of efficiency gains obtained by manipulating cost-driving variables both under the control of the operators (trains and drivers productivity) and of the Local Authority who assigns the service (number of TRK assigned within the service contract and the number of opening hours per station). These examples show how the Local Authority should allocate extra-resources if it wants to increase the quality-quantity mix of metro services.
\end{abstract}

Keywords: standard costs, local public transport, light metro, heavy metro.

\section{INTRODUCTION}

Standard cost reflects the cost of a local public transport (LPT) service with a specified service quality and provided by an efficient operator. The "efficiency levels can be estimated on the basis of the activities and costs of several operators (top-down or econometric approach) and/or by building up the cost function of a specified service moving from the detailed knowledge of the industrial process (bottom-up or engineering approach).

Only a bunch of papers has dealt with the specific definition and measurement of the standard cost of LPT services, mainly focusing on bus operations, e.g., [1]-[6]. Conversely, a vast literature explores the cost structure of bus transit and railroad systems (see [7] for a literature review). Several models have been put forward for choosing the public transport technology, such as bus rapid transit, light metro (LM) and heavy metro (HM), based on cost considerations. [8] introduces a parametric cost model for bus rapid transit and light metro services in order to compare these two technologies for peak and off-peak services in trunk lines. Estimates used are not representative of any specific operating context but are based on representative performance statistics provided by the Dallas Area Rapid Transit agency. [9] perform a cost-benefit analysis to evaluate an upgrade from an existing bus technology to LM technology. Estimates are based on typical values from the literature. [10], based on the case study of [11] for a transit line in Australia, undertake a comparative study of four modes: conventional buses, bus rapid transit, LM and HM. The calculation of the unit cost values is based on infrastructure and rolling stock costs, operational costs and overheads. Again, estimates are not representative of any specific operating context, but are based on values recommended by the National Guidelines for Transport System Management in Australia. To the best of our knowledge, [12] is the only paper which defines a formal procedure for gauging the standard cost of LM and HM services despite the ever-larger role 
of these services especially in large and medium-sized cities. The authors make use of a detailed data set in order to derive the cost model: economic and transport data for LM and HM services have been gathered by means of questionnaires sent to companies producing $100 \%$ of train revenue kilometers (TRK) in Italy in 2012. By doing so, they have been able to fairly compute the total economic cost of LM and HM services rather than provide estimates based on representative performance statistics. In particular, the total economic cost is derived by taking into account technological characteristics that may drive cost differentials, such as the degree of automatism, wheels technology and hourly peak capacity.

In this paper, we contribute to the literature as we measure the standard cost of LM and HM Italian services based on the cost model provided by [12]. Specifically, we focus on three case studies: (i) not automatic railway steel technology with heavy capacity; (ii) not automatic railway steel technology with light capacity; (iii) automatic rubber-tyred technology with light capacity. We also perform a simulation study in order to highlight the marginal impact of efficiency gains obtained by manipulating cost-driving variables both under the control of the operators (trains and drivers productivity) and of the Local Authority who assigns the service (number of TRK assigned within the service contract and the number of opening hours per station). These examples show how the Local Authority should allocate extra-resources if it wants to increase the quality-quantity mix of metro services. Our results might then be used to define the maximum economic compensation (auction base) in competitive tendering procedures or a benchmark for the bargaining with the local monopolist. Tendering procedures are a common way to award monopoly franchises in utilities (see also [13], [14]). The paper is organized as follows. Section 2 briefly describe the cost model. Section 3 presents case studies and sensitivity analysis. Section 4 concludes.

\section{THE COST MODEL}

In this section, we briefly describe the cost model developed in [12] for LM and HM services. We remark that the Italian Standard Organization (UNI) defines HM and LM services (UNI 8379:2000 regulation) with respect to the capacity for traffic volume. The minimum hourly peak capacity of HM services is equal to 24,000 seats hour. As opposite, the minimum hourly peak capacity of LM services transport system is equal to 8,000 seats hour (and lower than 24,000 seats hour).

The cost model lays on a hybrid approach which combines bottom-up and top-down techniques with respect to different cost categories. The bottom-up approach is adopted for the estimation of crucial cost categories, which mainly drive unjustified past inefficiencies. Conversely, the top-down approach is adopted whenever a full description of the technology underlying some category of expenses is not available or the modelling process is time consuming in comparison to the significance of cost components.

The crucial technological characteristics which drive cost differentials are the following.

- The degree of automatism influences the cost of the driving personnel.

- Wheels Technology influences the economic cost of the rolling cost (including the cost of fleet use, traction power, train maintenance and the cost of capital), with the cost of a railway steel rolling stock being higher of the cost of a rubber-tyred rolling stock.

- The network that characterizes the provision of LM services is usually associated with a limited number of stations and a reduced line length. The length of trains influence gross driving hours, which value hours spent in turnarounds at the end of line and time spent to store trains to the depots. Indeed, the higher is the dimension 
of the train the higher is time spent by the driver walking alongside the loading platform.

For a given service provided in a given year, the standard cost of the service, $\bar{C}$, is estimated as the sum of: (i) the standard cost of the transport activities production, $\bar{C}_{\text {tra }}$; (ii) the standard cost related to the use of the infrastructure, $\bar{C}_{\text {inf }}$; (iii) the overall overheads, $\bar{C}_{o h}$; and (iv) the standard cost of the net invested capital, $\bar{C}_{\text {cap }}$

$$
\bar{C}=\bar{C}_{t r a}+\bar{C}_{i n f}+\bar{C}_{o h}+\bar{C}_{c a p}
$$

We may derive the standard cost per train revenue kilometer as:

$$
\bar{C}_{T R K}=\frac{\bar{C}}{T R K} \text {. }
$$

The categories of expenses counted in the cost basis are described in Table 1.

While we refer the reader to the [12] for details on the calculation of single cost items, we here specify details the calculation of the cost of the driving personnel, $\bar{C}_{d r i}$, cost of the staff dedicated to movement activities and station agents, $\bar{C}_{\text {mov_sta }}$, and the cost of the rolling

\begin{tabular}{|c|c|c|}
\hline Expenses & & Cost items \\
\hline $\begin{array}{l}\text { Transport } \\
\text { services }\end{array}$ & $\bar{C}_{t r a}$ & 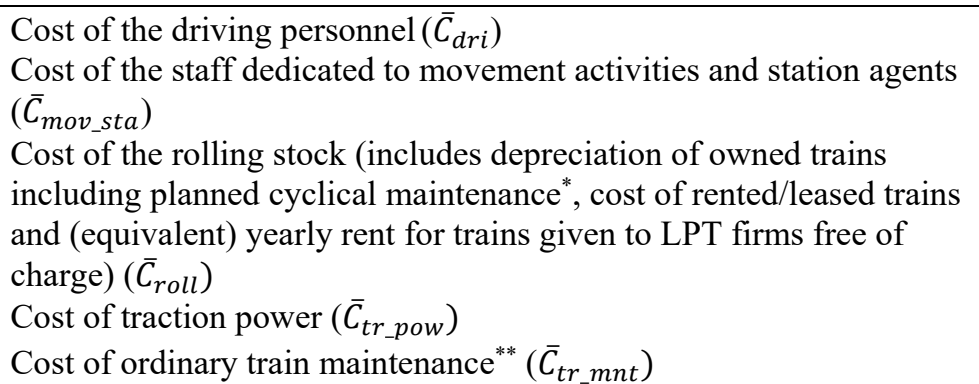 \\
\hline Infrastructure & $\bar{C}_{\text {inf }}$ & $\begin{array}{l}\text { Cost of power }\left(\bar{C}_{\text {sta_pow }}\right) \\
\text { Cost of infrastructure (stations and depots), including depreciation, } \\
\text { rents and leasing charges }\left(\bar{C}_{i_{-} u s e}\right) \\
\text { Cost of ordinary infrastructure maintenance }\left(\bar{C}_{i \text { mnt }}\right)\end{array}$ \\
\hline Overheads & $\bar{C}_{o h}$ & $\begin{array}{l}\text { Overall management, economic planning and control costs, } \\
\text { membership fees, business consulting and information systems costs, } \\
\text { other labour cost for personnel employed in overhead activities, cost } \\
\text { of overhead activities outsourced to third parties }\end{array}$ \\
\hline $\begin{array}{l}\text { Cost of } \\
\text { Capital }\end{array}$ & $\bar{C}_{c a p}$ & $\begin{array}{l}\text { The cost of capital invested in the rolling stock }\left(\bar{C}_{\text {cap_roll }}\right) \\
\text { The cost of capital invested in the infrastructure }\left(\bar{C}_{\text {cap_inf }}\right) \\
\text { The cost due to the Regional Business Tax levied on the value of } \\
\text { production generated in each tax period }\left(\bar{C}_{\text {irap }}\right)^{* * *}\end{array}$ \\
\hline
\end{tabular}

Table 1: Cost items included in the standard cost basis.

${ }^{*}$ Planned cyclical maintenance increases the book value of the asset, which raises depreciation expenses in future periods. For this reason, such maintenance is capitalized.

${ }^{* *}$ It includes the cost of maintenance outsourced to third parties, the cost of spare parts, labour costs for in-house maintenance, the cost of equipment, machinery and other fixed assets used for in-house maintenance within the fiscal year.

*** The Regional Business Tax impacts production in relation to the earnings produced before labour costs and financial income and expenses. In 2012, Italian Regions set the ordinary rate of IRAP at 3.9\%. 
stock, $\bar{C}_{\text {roll }}$, which can be obtained by manipulating cost-driving variables both under the control of the operators (trains and drivers productivity) and of the Local Authority assigning the service (number of TRK assigned within the service contract and the number of opening hours per station). The cost of the driving personnel can be calculated as:

$$
\bar{C}_{d r i}=\bar{n}_{d r i} \cdot \beta_{d r i},
$$

where:

- $\bar{n}_{d r i}$ is the standard number of drivers.

- $\quad \beta_{d r i}$ is the standard unit cost of the driving personnel, i.e., per driver. It includes health and social insurance, and retirement funds. [12] finds $\beta_{d r i}=$ $55,000.45 € /$ driver for a sample of 2012 data on Italian LM and HM (not automatic) services.

Obviously, this cost item is null in case of services operated through automatic technology. In particular, the standard number of drivers can be approximately derived from the standard number of gross driving hours as follows:

$$
\bar{n}_{d r i}=\frac{T K}{\beta_{g h} \cdot\left(V \cdot \beta_{v}\right)},
$$

where:

- $\quad T K=T R K+T K_{\varnothing}$, with $T K_{\varnothing}$ being the number of train kilometers produced out of service (that is in turnarounds at the end of the line and to store trains in depots).

- $\quad \beta_{g h}$ is the standard number of gross driving hours per driver (i.e., standard driver's productivity). This parameter values hours spent in driving $\mathrm{TRK}$ and $\mathrm{TK}_{\emptyset}$. [12] finds $\beta_{g h}=892 \mathrm{~h} /$ driver and $\beta_{g h}=1,221.85 \mathrm{~h} /$ driver for a sample of 2012 data on Italian HM and LM (not automatic) services, respectively.

- $\quad V$ is the commercial speed defined as the ratio between TRK and the total number of net driving hours (i.e., from end to end of the line).

- $\quad \beta_{v}$ represents a coefficient to adjust the commercial speed in order to take into account also the impact of train kilometers produced out of service and corresponding driving hours. [12] finds $\beta_{v}=0.8576$ and $\beta_{v}=0.6530$ for a sample of 2012 data on Italian HM and LM (not automatic) services, respectively, and $\beta_{v}=$ 0.9896 for a sample of 2012 data on Italian LM (automatic) services.

The cost of the staff dedicated to movement activities and station agents can be calculated as:

$$
\bar{C}_{\text {mov_sta }}=\bar{n}_{\text {mov_sta }} \cdot \beta_{\text {mov_sta }},
$$

where:

- $\bar{n}_{\text {mov_sta }}$ is the standard number of staff dedicated to movement activities and station agents.

- $\quad \beta_{\text {mov_sta }}$ is the standard unit cost of the staff dedicated to movement activities and station agents, i.e., per unit of staff. It includes health and social insurance, and retirement funds. [12] finds $\beta_{\text {mov_sta }}=49,834.02 € /$ work units for a sample of 2012 data on Italian LM and HM services. 
In particular, the standard number of staff dedicated to movement activities and station agents can be derived as follows:

$$
\bar{n}_{m o v_{-} s t a}=N_{s t a} \cdot H_{s t a} \cdot \beta_{n \_m o v \_s t a},
$$

where:

- $\quad N_{\text {sta }}$ is the number of stations on the line.

- $H_{\text {sta }}$ is the number of opening hours per station.

- $\quad \beta_{n \_m o v \_s t a}$ is the standard number of staff dedicated to movement activities and station agents per station opening hour and per station. [12] finds $\beta_{n_{-} \text {mov_sta }}=$ 0.000993 work units $/ \mathrm{h} \cdot$ station and $\beta_{n \_ \text {mov_sta }}=0.000489$ work units $/ \mathrm{h} \cdot$ station for a sample of 2012 data on Italian HM and LM services, respectively.

Finally, the cost of the rolling stock can be calculated as:

$$
\bar{C}_{\text {roll }}=\bar{n}_{t r} \cdot S_{t r} \cdot \beta_{\text {depr_s }},
$$

where:

- $\bar{n}_{t r}$ is the standard number of trains and $S_{t r}$ is the number of seats per train.

- $\beta_{\text {depr } s}$ is the standard train depreciation per seat. It depends on the capacity, degree of automatism and wheels technology. [12] finds $\beta_{\text {depr_s }}=244.57 € /$ seat, $\beta_{\text {depr } \_s}=312.50 € /$ seat and $\beta_{\text {depr } \_s}=102.27 € /$ seat for a sample of 2012 data on Italian HM not automatic railway steel, LM not automatic railway steel and LM automatic rubber-tyred services, respectively.

In particular, the standard number of trains used to provide the service can be calculated as follows:

$$
\bar{n}_{t r}=\frac{T K}{\beta_{\text {tr_prod }}}
$$

where:

- $\quad \beta_{\text {tr_prod }}$ is the standard number of train kilometers produced per train, including TRK and train kilometers produced out of service, i.e., standard train's productivity. [12] finds $\beta_{\text {tr_prod }}=90.000 \mathrm{~km} /$ train for a sample of 2012 data on Italian metro services.

\section{CASE ANALYSIS}

In order to illustrate how our results might be used at a micro-level to define a maximum economic compensation we build some case studies. We focus on three different cases according to the degree of automatism, the capacity and wheels technology. In particular, we remark that the hybrid cost model makes use of variables and standard parameters. Variables represent specific features of the selected service which can justify cost differentials. The variables representing specific features of our case studies are not representative of any specific operating context but are based on reasonable assumptions over the Italian metropolitan areas. Conversely, standard parameters represent efficiency requirements in the production process. These standard parameters are estimated fitting instances included in our Database. 


\subsection{Data}

Disaggregated information about costs, technical and environmental characteristics for the calculation of standard parameters of the cost models have been collected in 2012 by means of questionnaires sent to Italian companies providing local underground public transportation services in 5 Italian Regions and producing more than 21 million of TRK, i.e., $100 \%$ of the production of LM and HM services in 2012. Table 2 displays some indicators characterizing services observed in 2012 (the coefficient of variation is calculated as the ratio between the standard deviation and the mean). The number of TRK is a good proxy of the overall size of the service.

\subsection{Case studies}

Let us assume that the following services are auctioned off by means of a tendering procedure (i.e., variable parameters of the cost model, see Table 3). The first one relates to the assignment of 10,500,000 TRK; the second one relates to the assignment of 4,300,000 TRK. Both services are operated through not automatic railway steel technology, the former being a heavy capacity service while the latter being a light capacity service. Table 4 shows the result of our model in the case of heavy capacity services. Similarly, Table 5 shows the results in the case of light capacity services. On the basis of the results, the maximum economic compensation that can be required by any firm for the provision of services operated through not automatic railway steel technology is $30.65 € / \mathrm{km}$ and $17.60 € / \mathrm{km}$ in the case of heavy capacity and light capacity respectively.

Let us assume, now, that a service is auctioned off by means of a tendering procedure for the assignment of 3,000,000 TRK. Let consider the case in which the service is characterized by light capacity and operated through automatic rubber-tyred technology (Table 6). Table 7 shows the results. On the basis of the results, the maximum economic compensation that can be required by any firm for the provision of the described service is $11.08 € / \mathrm{km}$.

Table 2: Productivity indicators of LM and HM services included in the database.

\begin{tabular}{|c|c|c|c|c|c|c|}
\hline & & Mean & $1^{\circ}$ quartil & Median & $3^{\circ}$ quartil & $\begin{array}{l}\text { Coeff. of } \\
\text { variation }\end{array}$ \\
\hline TRK & {$[\mathrm{Km}]$} & $\begin{array}{c}3,064,177 . \\
21\end{array}$ & $276,796.75$ & $\begin{array}{c}1,038,285 \\
00\end{array}$ & $\begin{array}{c}4,651,932 . \\
25\end{array}$ & 1.31 \\
\hline $\begin{array}{l}\text { Train-km produced } \\
\text { out of service }\end{array}$ & {$[\mathrm{Km}]$} & $92,052.12$ & $3,461.70$ & $8,118.00$ & $145,049.13$ & 1.46 \\
\hline $\begin{array}{l}\text { Net driving hours/ } \\
\text { Gross driving hours }\end{array}$ & & 0.77 & 0.67 & 0.75 & 0.83 & 0.15 \\
\hline Commercial speed & {$[\mathrm{Km} / \mathrm{h}]$} & 29.16 & 28.63 & 30.00 & 31.24 & 0.11 \\
\hline Vehicle productivity $^{\mathrm{c}}$ & $\begin{array}{l}{[\mathrm{Km} /} \\
\text { train] }\end{array}$ & $64,932.94$ & $45,140.98$ & $69,760.20$ & $91,702.76$ & 0.56 \\
\hline Drivers & & 142.99 & 15.80 & 34.40 & 44.53 & 52.57 \\
\hline Drivers productivity & $\begin{array}{c}{[\mathrm{h} /} \\
\text { driver] }\end{array}$ & 902.80 & 834.64 & 895.56 & $1,112.22$ & 0.33 \\
\hline
\end{tabular}


Table 3: Case studies: hypothetical characteristics of the LM and HM services operated through not automatic railway steel technology.

\begin{tabular}{|c|c|c|c|}
\hline Capacity & & Heavy & Light \\
\hline \multicolumn{4}{|c|}{ Transport characteristics } \\
\hline TRK & {$[\mathrm{km}]$} & $10,500,000$ & 430,000 \\
\hline$T K_{\varnothing}$ & {$[\mathrm{km}]$} & 200,000 & 5,000 \\
\hline$V$ & {$[\mathrm{~km} / \mathrm{h}]$} & 27 & 29 \\
\hline$S_{t r}$ & [seats/train] & 1,250 & 410 \\
\hline \multicolumn{4}{|c|}{ Infrastructure characteristics } \\
\hline $\begin{array}{l}N_{\text {mov }} \\
N_{\text {sta }} \\
H_{\text {sta }}{ }^{\mathrm{a}}\end{array}$ & {$[\mathrm{h}]$} & $\begin{array}{l}530 \\
95 \\
6,700\end{array}$ & $\begin{array}{l}40 \\
7 \\
5,500\end{array}$ \\
\hline
\end{tabular}

${ }^{a}$ On average, it corresponds to 18 hours and 15 hours per day, respectively.

Table 4: Case studies: standard unit cost of the HM service operated through not automatic railway steel technology.

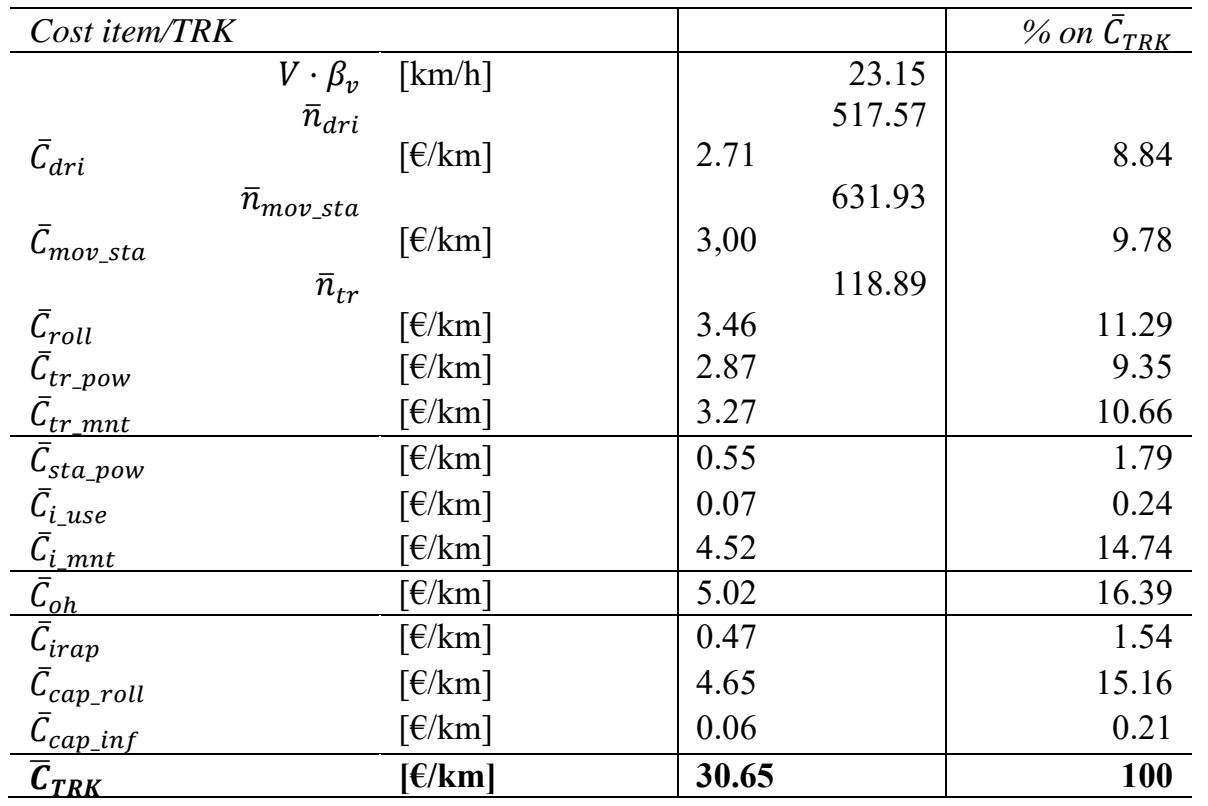

\subsection{Sensitivity analysis}

In this section, we perform a simulation study in order to highlight how the standard cost of the service changes when the required levels of efficiency are tuned according to some regional objective. In particular, we show the marginal impact of efficiency gains obtained with respect to cost-driving variables both under the control of the operators and of the Local Authority who assigns the service. Examples clarify how the cost of the service may differ significantly among operators which introduced different efficiency gains in the use of inputs (drivers and trains). Similarly, our simulation clarify how the Local Authority should allocate 
Table 5: Case studies: standard unit cost of the LM service operated through not automatic railway steel technology.

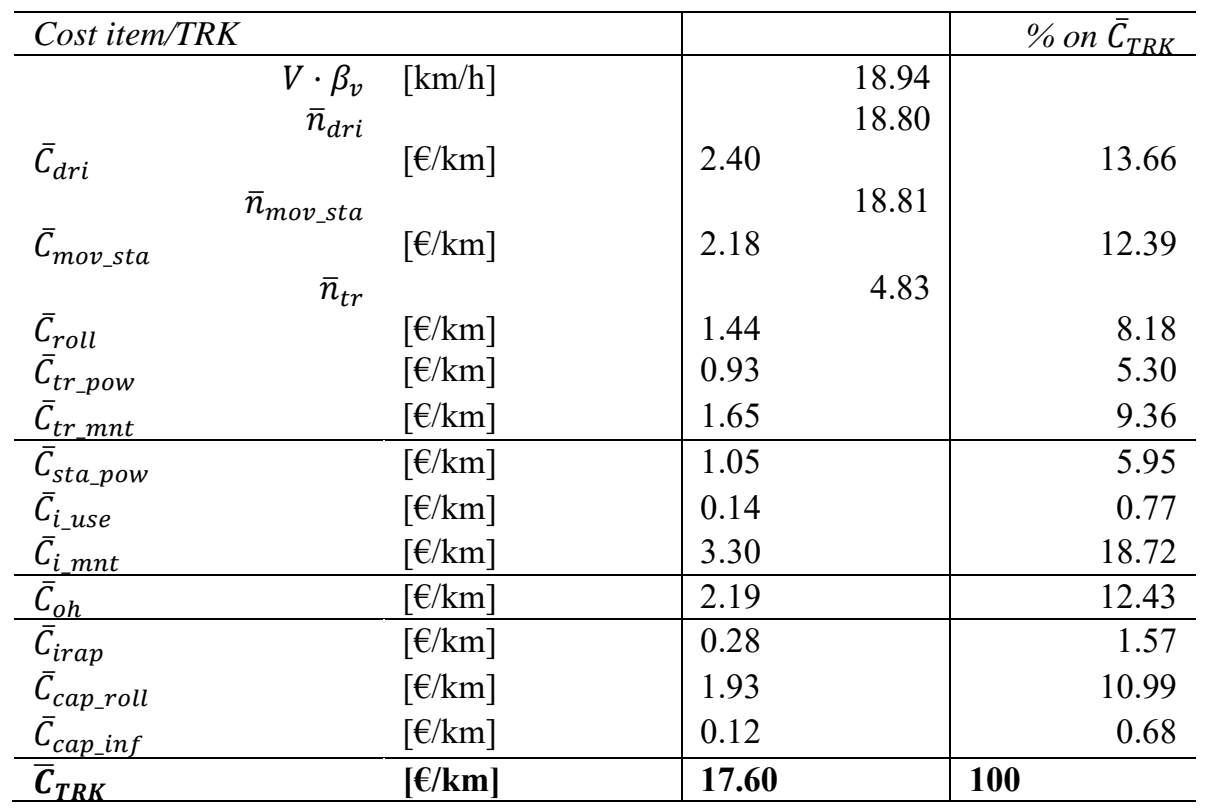

Table 6: Case studies: hypothetical characteristics of a LM service operated through automatic rubber-tyred technology.

\begin{tabular}{ll|r}
\hline Transport characteristics & \multicolumn{2}{c}{} \\
\hline TRK & {$[\mathrm{km}]$} & $2,800,000$ \\
$T K_{\varnothing}$ & {$[\mathrm{km}]$} & $3,080,000$ \\
$V$ & {$[\mathrm{~km} / \mathrm{h}]$} & 30 \\
$S_{t r}$ & {$[$ seats/train] } & 430 \\
\hline Infrastructure characteristics & 196 \\
\hline$N_{\text {mov }}$ & 24 \\
$N_{\text {sta }}$ & 6,700 \\
$H_{\text {sta }}{ }^{\mathrm{a}}$ &
\end{tabular}

higher resources if it wants to increase the quality of the service in terms, for instance, of a higher number of opening hours per station per day. For the sake of space and readability we perform our simulations on the basis of a single case study, specifically a heavy capacity service operated through not automatic railway steel technology (see Table 3 and 4). We first focus on cost-driving variables under the control of the operators. In particular, we analyze the marginal impact of trains and drivers productivity on the standard cost, i.e., $\beta_{\text {tr_prod }}$ and $\beta_{g h}$ respectively (see eqns (3) and (7)).

Fig. 1 shows how the standard cost and related savings vary when there is a percentage increase of train kilometers produced per train, other characteristics being fixed. For instance, a $5 \%, 10 \%, 20 \%, 30 \%$ increase of train kilometers produced per train, respectively, leads to a reduction of unit standard costs which is almost equal to: $38.6,73.7,135.1,187.1 €$ cent $/ \mathrm{km}$. 
Table 7: Case studies: standard unit cost of a LM service operated through automatic rubber-tyred technology.

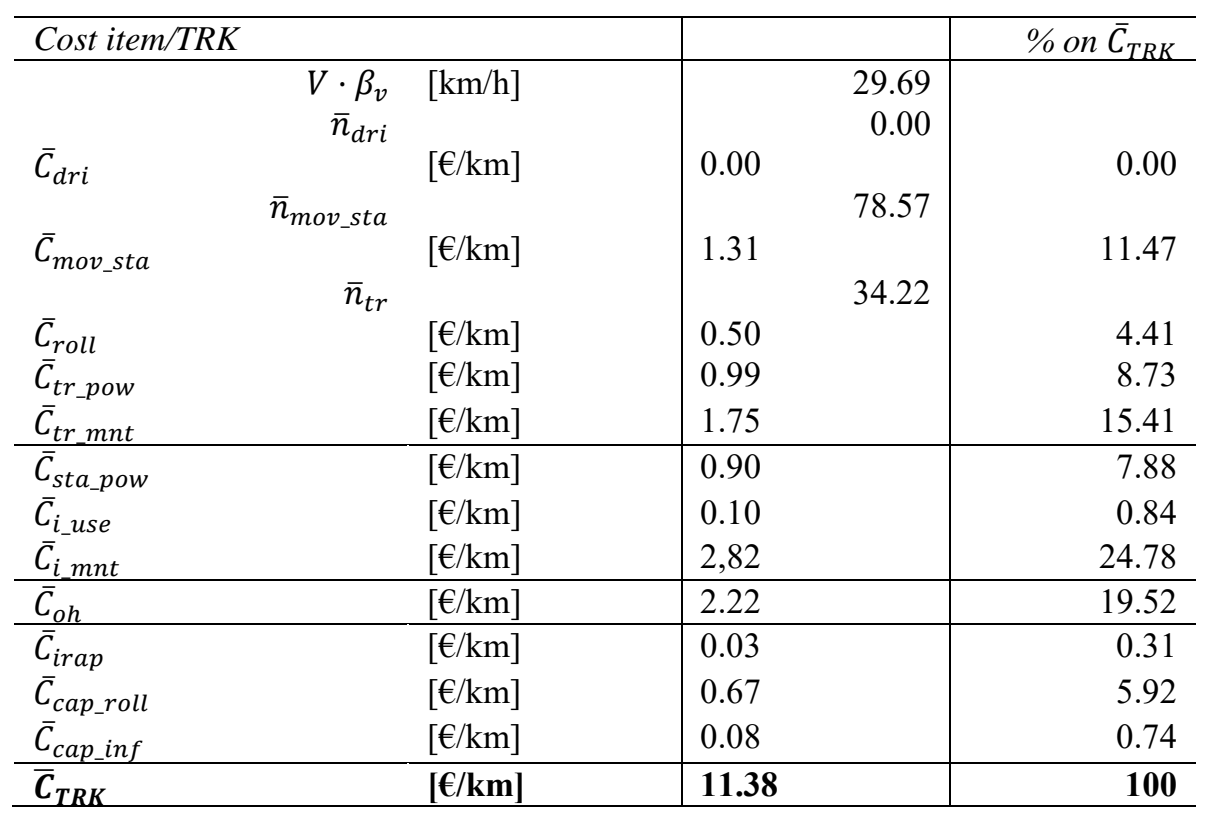

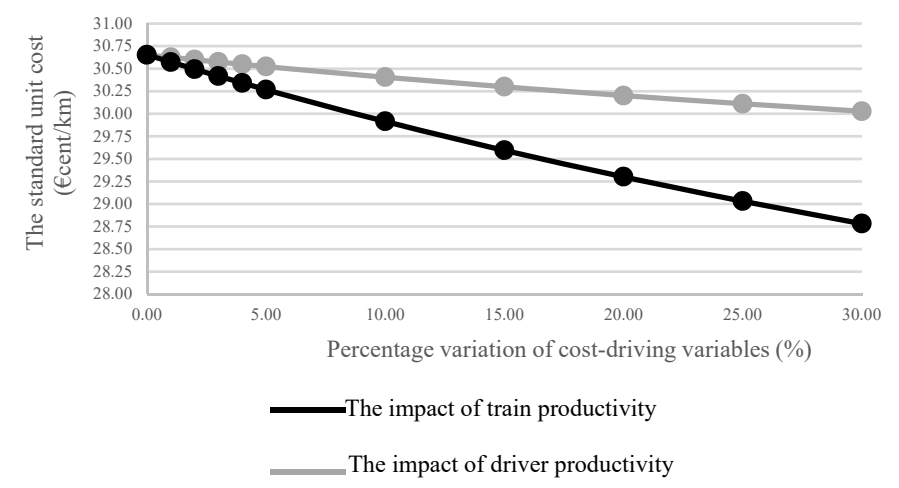

Figure 1: Variations in the standard unit cost due to efficiency gains in driver and train productivity.

We note that savings in the unit standard cost are higher when efficiency is pursued with respect to train productivity, rather than driver productivity (see Fig. 1). In fact, LM and HM services are asset intensive rather labour intensive: the economic cost of the rolling stock together with the cost of fleet use, traction power, train maintenance and the cost of capital cover more than $45 \%$ of the total economic cost (cfr. Table 4 ). We now focus on cost-driving variables under the control of the Local Authority. In particular, we analyze the marginal impact of the number of train revenue kilometers assigned within the service contract, i.e., TRK, and the number of opening hours per station, $H_{\text {sta }}$. Indeed, the number of opening 


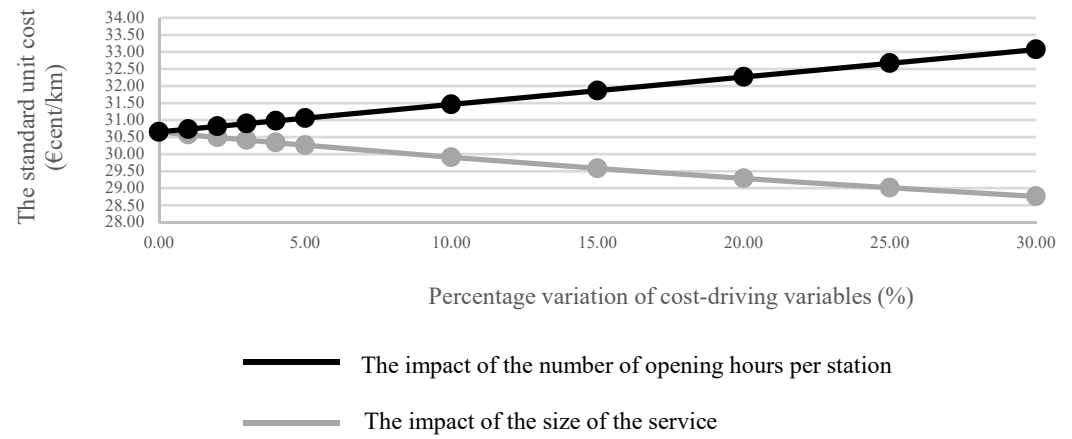

Figure 2: Variations in the standard unit cost due to changes in the size of the service and the number of stations opening.

hours per stations affects the cost of infrastructure power usage and maintenance. Fig. 2 shows how the standard cost and related savings vary when there is a percentage increase of TRK, other characteristics being fixed. For instance, a 5\%, 10\%, 20\%, 30\% increase of TRK, respectively, leads to a reduction of unit standard costs which is almost equal to: $39.4,74.55$, $136.70,189.28 €$ cent $/ \mathrm{km}$.

The unit standard cost reduces as the size of the service increases as scale economies play a role: the firm obtains cost advantages as infrastructure costs (including the cost of infrastructure use and maintenance, station power, and the cost of capital) are spread out over a higher scale of operation. Similarly, Fig. 2 also shows how the standard cost and related savings vary when there is a percentage increase of the number of opening hours per station other characteristics being fixed. For instance, a 5\%, 10\%, 20\%, 30\% increase of the number of opening hours per station, respectively, leads to an increase of unit standard costs which is almost equal to: $40.3,80.7,161.3,242 €$ cent $/ \mathrm{km}$. This example clarifies how the Local Authority should allocate extra-resources if it wants to increase the quality of the service in terms, for instance, of a higher number of opening hours per station per day.

\section{CONCLUSIONS}

In this paper, we measure the standard cost of LM and HM Italian services. Specifically, we make use of the cost model provided by [12] and we focus on three case studies: (i) not automatic railway steel technology with heavy capacity; (ii) not automatic railway steel technology with light capacity; (iii) automatic rubber-tyred technology with light capacity. We also perform a simulation study in order to highlight the marginal impact of efficiency gains obtained by manipulating cost-driving variables both under the control of the operators (trains and drivers productivity) and of the Local Authority assigning the service (number of TRK assigned within the service contract and the number of opening hours per station).

We find that savings in the unit standard cost are higher when efficiency is pursued with respect to train productivity, rather than driver productivity. Moreover, we find that the unit standard cost decreases as the size of the service increases, since scale economies play a role.

\section{REFERENCES}

[1] Dalen, D.M. \& Lobo, A.G., Yardsticks on the road: Regulatory contracts and cost efficiency in the Norwegian bus industry. Transportation, 30(4), pp. 371-386, 2003. DOI: $10.1023 / \mathrm{A}: 1024784517628$. 
[2] Hensher, D.A., Mulley, C. \& Smith, N., Towards a simplified performance-linked value for money model as a reference point for bus contract payments. Research in Transportation Economics, 39(1), pp. 232-238, 2013.

DOI: $10.1016 /$ j.retrec.2012.06.018.

[3] Avenali, A., Boitani, A., Catalano, G., D’Alfonso, T. \& Matteucci, G., Un modello per la determinazione del costo standard nei servizi di trasporto pubblico locale su autobus in Italia. Economia e Politica Industriale, 4, pp. 181-213, 2014.

[4] Avenali, A., Boitani, A., Catalano, G., D’Alfonso, T. \& Matteucci, G., Assessing standard costs in local public bus transport: Evidence from Italy. Transport Policy, 52, pp. 164-174, 2016. DOI: 10.1016/j.tranpol.2016.06.007.

[5] Avenali, A., Catalano, G., D’Alfonso, T., Matteucci, G. \& Manno, A., Key-cost drivers selection in local public bus transport services through machine learning. WIT Transactions on the Built Environment, vol. 176, WIT Press: Southampton and Boston, pp. 155-166, 2017.

[6] Avenali, A., Boitani, A., Catalano, G., D’Alfonso, T. \& Matteucci, G., Assessing standard costs in local public bus transport: A hybrid cost model. Transport Policy, 62, pp. 48-57, 2018. DOI: 10.1016/j.tranpol.2017.03.011.

[7] Daraio, C., Diana, M., Di Costa, F., Leporelli, C., Matteucci, G., \& Nastasi, A., Efficiency and effectiveness in the urban public transport sector: A critical review with directions for future research. European Journal of Operational Research, 248(1) pp. 1-20, 2016. DOI: 10.1016/j.ejor.2015.05.059.

[8] Bruun, E., Bus rapid transit and light metro: Comparing operating costs with a parametric cost model. Transportation Research Record: Journal of the Transportation Research Board, 1927(1), pp. 11-21, 2005.

DOI: $10.1177 / 0361198105192700102$.

[9] Grimaldi, R., Beria, P. \& Laurino, A., Stylised cost-benefit model for the choice between bus and light metro. Journal of Transport Economics and Policy, 48(2), pp. 219-239, 2014.

[10] Moccia, L. \& Laporte, G., Improved models for technology choice in a transit corridor with fixed demand. Transportation Research Part B: Methodological, 83, pp. 245270, 2016. DOI: 10.1016/j.trb.2015.11.001.

[11] Tirachini, A., Hensher, D.A. \& Jara-Díaz, S.R., Restating modal investment priority with an improved model for public transport analysis. Transportation Research Part E: Logistics and Transportation Review, 46(6), pp. 1148-1168, 2010. DOI: 10.1016/j.tre.2010.01.008.

[12] Avenali, A., Boitani, A., Catalano, G., D’Alfonso, T. \& Matteucci, G., A hybrid cost model for metro services, Mimeo, 2018.

[13] Garrone, P. \& Marzano, R., Why do local governments resist contracting out? Urban Affairs Review, 51(5), pp. 616-648, 2015.

[14] Marzano, R., One more ride on the merry-go-round! Public ownership and delayed competition in local public services. Journal of Comparative Economics, 43(4), pp. 981-996, 2015. 